\title{
Analysis of histopathology results of ASCUS and LSIL cytology in HPV DNA positive cases
}

\section{ASCUS ve LSIL sitolojilerinin histopatoloji sonuçlarının HPV DNA pozitif olgularda incelenmesi}

\author{
Ibrahim Yalcin, Hanifi Sahin, Mustafa Erkan Sarı, Mehmet Mutlu Meydanlı, Tayfun Güngör \\ Sağlık Bilimleri Üniversitesi Tıp Fakültesi, Zekai Tahir Burak Eğitim Ve Araştırma Hastanesi, \\ Jinekolojik Onkoloji Kliniği, Ankara, Türkiye
}

Dergiye Ulaşma Tarihi:04.03.2018 Dergiye Kabul Tarihi:10.04.2018 Doi: 10.5505/aot.2018.39206

\section{ÖZET}

GİRIŞ ve AMAÇ: HPV DNA kullanılarak yapılan ulusal servikal kanser tarama programı ışı̆̆ında ASCUS ve LSIL sitoloji sonucuna sahip HPV DNA pozitif kadınların kolposkopi sonrası histopatoloji sonuçlarının incelenmesi.

YÖNTEM ve GEREÇLER: Bu çalışma Zekai Tahir Burak Kadın Sağlığı Eğitim ve Araştırma Hastanesi Jinekolojik Onkoloji Kliniğinde Temmuz 2016 ile Ocak 2018 arasında arasında gerçekleş̧irildi. Hastaların kayitları retrospektif olarak tarand. Çalışmaya servikal kanser tarama testinde ASCUS ve ya LSIL sitolojisine sahip olan ve HPV DNA pozitif olan 30 - 65 yaş arası 178 olgu dahil edildi.

BULGULAR: Hastaların ortalama yaşı 41 idi. 178 hastanın yüz on birinin sitolojisi ASCUS altmış yedisinin sitolojisi LSIL idi. ASCUS ve LSIL grupları arasında yaş, histopatoloji, HPV DNA tipi ve cerrahi sınır pozitifliği açısından istatistiksel olarak anlamlı bir farklılık bulunmamaktaydı (sırasıyla $\mathrm{p}=0.49, \mathrm{p}=0.25, \mathrm{p}=0.15$ ve $\mathrm{p}=0.17)$.

TARTIŞMA ve SONUÇ: HPV DNA pozitif ASCUS ve LSIL olguları arasında HSIL ve üzeri servikal patoloji bulunma oranı farklılık göstermemektedir.

Anahtar Kelimeler: Düşük grade skuamöz intraepitelyal lezyon, Human papilloma virüs, Önemi belirsiz atipik skuamöz hücreler, Yüksek grade skuamöz intraepitelyal lezyon

ABSTRACT
INTRODUCTION: Aim: To analyze colposcopic histopathology results of HPV DNA positive women with ASCUS and LSIL cytology in the era of national HPV based cervical cancer screening program

METHODS: This study was conducted in Zekai Tahir Burak Women's Health Research and Training Hospital Gynecological Oncology Clinic between July 2016 and January 2018. The patient records were retrospectively reviewed. 178 patients aged between 30 and 65 years with ASCUS or LSIL cytology and HPV DNA positive were included in this study.

RESULTS: The mean age of the patients were 41 years. 178 hastanın yüz on birinin sitolojisi ASCUS altmış yedisinin sitolojisi LSIL idi. Out of 178 woman in total, primarily referring 111 were positive for ASCUS cytology, 67 were positive for LSIL cytology. There was no statistically significant difference in regard to age, histopathology, HPV DNA type and surgical cone margin positivity between two groups $(p=0.49, p=0.25$, $\mathrm{p}=0.15$, ve $\mathrm{p}=0.17$, respectively).

DISCUSSION and CONCLUSION: The incidence of HSIL and over cervical pathology is not different between HPV DNA positive ASCUS and LSIL cases.

Keywords: Atypical squamous cells of undetermined significance, High-grade squamous intraepithelial neoplasia, Human papillomavirus, Low-grade squamous intraepithelial neoplasia.

\section{GíRiș}

ATHENA (Addressing the Need for Advanced HPV Diagnostics) çalışmasıyla birlikte HPV DNA testinin servikal kanser taramasındaki etkinliği gösterilmiştir (1). Ayrıca bu çalışma ile birlikte prevalansı yüksek olan HPV 16 ve/ve ya HPV 18 bulunan olgularda servikal prekanseröz lezyonların diğer yüksek riskli HPV'lere göre daha sik bulunduğu gösterilmiştir. Diğer HPV genotiplerini saptamanın önemi net olarak gösterilmese de güncel kılavuzlar 30 yaşın üstünde olan kadınlarda sitolojisi anormal ise HPV DNA 
tipine bakılmaksızın HPV DNA pozitifliğinde kolposkopik inceleme önermektedir (2).

Önemi belirsiz atipik skuamöz hücreler (ASCUS) ve düşük grade skuamöz intraepitelyal lezyonlar (LSIL) en s1k rastlanan iki servikal sitolojik anormalliktir (3). Bugüne kadar bildirilen iki büyük çalışmada HPV durumuna bakılmaksızn ASCUS ve LSIL sitolojilerine sahip olan kadınların sırasıyla 5 y1l içerisindeki CIN 2 ve üzeri riski $\% 6.9$ ve $\% 16$, CIN 3 ve üzeri riski $\% 2.6$ ve $\% 5.2$, servikal kanser riski \%0.18 ve \%0.16 olarak bildirilmiştir $(4,5)$. Sadece Monsonego ve ark. anormal sitolojiyle beraber HPV tiplerine göre biyopsi sonuçlarını bildirmişlerdir (6). Fakat bu çalışmada bütün anormal sitolojiler beraber bir grup olarak incelenmişlerdir.

Bizim bu çalışmamızın amacı ASCUS ve LSIL sitolojilerine eşlik eden HPV tiplerini belirlemek ve bu iki sitolojik grubu HPV tipleri ve kolposkopi sonrası histopatolojik sonuçlar açısından karşılaştırmaktır.

\section{GEREÇ ve YÖNTEM}

Bu çalışma Zekai Tahir Burak Kadın Sağlığı Eğitim ve Araştırma Hastanesi Jinekolojik Onkoloji Kliniğinde Haziran 2016 ile Ocak 2018 arasındaki hastalar arasından retrospektif olarak gerçekleştirildi. Çalışma için hastane lokal etik kurulundan onay alındı. Kanser erken teşhis ve tarama merkezlerinden (KETEM) jinekolojik onkoloji polikliniğine yönlendirilen 30-65 yaş arası, servikal kanser tarama testinde sitolojisi ASCUS veya LSIL olup HPV DNA's1 pozitif olan olgular çalışmaya dahil edildi. 30 yaş altı olgular, sitolojisi ASCUS ve LSIL dişı olan olgular, HPV DNA sonucu olmayan olgular çalışmaya dahil edilmedi.

Kolposkopiler dört jinekolojik onkolog tarafından gerçekleştrildi. Kolposkopi için Mikro Kolposkop Leica M60 (MIKRO, Prag, Çek Cumhuriyeti) kullanıldı. Servikse \%3 asetik asit uygulandıktan sonra şüpheli gözüken alanlardan servikal biyopsi alındı ve endoservikal küretaj uyguland1 (7). Hastanemiz servikal kanser tarama programı doğrultusunda yüksek riskli HPV DNA pozitif olgularda kolposkopi sonrası şüpheli görünüm olmayanlarda serviks saat 12 ve 6 hizasindan biyopsi alınarak endoservikal küretaj uyguland. Cerrahi spesimenler 3 jinekolojik patolog tarafindan LAST terminolojisi kullanılarak değerlendirildi (8).

Kolposkopik biyopsi sonucu HSIL olan olgulara konizasyon uygulandi. Hastaların tanıları servikal biyopsi, endoservikal küretaj ve konizasyon sonrası çıkan en şiddetli histolojik sonuca göre normal, koilositiz, LSIL, HSIL ve servikal kanser olarak analiz edildi. ASCUS ve LSIL grupları yaş, servikal histopatoloji, HPV DNA tipi ve cerrahi sinır pozitifliği açısından karşılaştırldı.

İstatistiksel analiz SPSS versiyon 22 (SPSS Inc., Chicago, IL) kullanılarak yapıldı. Sayısal değişkenler dağılım durumuna göre (Kolmogorov-Smirnov/Shapiro-Wilk) ortanca kullanılarak, kategorik değişkenler ise yüzde oran olarak gösterildi. Gruplar arasındaki farkl111klar Mann Whitney U ve ki-kare veya fisher's exact testleri kullanılarak karşılaştırıldı. $\mathrm{P}$ değeri $<0.05$ olan durumlar istatistiksel olarak anlamlı kabul edildi.

\section{BULGULAR}

Çalışmaya toplam 178 hasta dahil edildi. Bu 178 hastanın yüz on birinin sitolojisi ASCSU altmış yedisinin sitolojisi LSIL idi. Ortalama yaş 41 idi. $76(\% 42.7)$ hasta $30-39$ yaş arası, 63 (\%35.4) hasta 40-49 yaş aras1, 28 (\%15.7) hasta 50-59 yaş arası, $11(\% 6.2)$ hasta ise $>60$ yaşındaydi.

Sitolojisi ASCUS olan yüz on bir hastanın histopatoloji sonuçları: $2(\% 1.8)$ hasta servikal kanser, 24 (\%21.6) hasta HSIL, 31 (\%27.9) hasta LSIL, 7 (\%6.3) hasta koilositoz ve $47(\% 42.3)$ hasta normal olarak saptand 1.

Sitolojisi LSIL olan altmış yedi hastanın histopatoloji sonuçları: 11 (\%16.4) hasta HSIL, 26 (\%38.8) hasta LSIL, 4 (\%6) hasta koilositoz ve 26 (\%38.8) hasta normal olarak saptandi.

ASCUS ve LSIL grupları arasında yaş, histopatoloji, HPV DNA tipi ve cerrahi sinır pozitifliği açısından istatistiksel olarak anlamlı bir farklılık bulunmamaktaydı (Tablo 1). Figür 1 ve 2 de ASCUS ve LSIL sitolojilerinde rastlanan HPV tiplerinin dağılımları gösterildi. ASCUS sitolojisine sahip olan olgularda HPV DNA 16 ve/veya 18 pozitifliğinde HSIL ve üzeri histopatoloji 20'ye (\%41.7) karşıllk diğer yüksek riskli HPV grubunda 7 (\%11.1) $(\mathrm{p}<0.001)$ iken, LSIL sitolojisine sahip olan olgularda HPV DNA 16 ve/ve ya 18 
pozitifliğinde HSIL ve üzeri histopatoloji 5 'e (\%23.8) karş1lık diğer yüksek riskli HPV grubunda $6(\% 13)$ olarak bulundu ( $\mathrm{p}=0.3)$.

Servikal biyopsi sonucu HSIL gelen 11 LSIL sitolojisine sahip hastanın sekiz tanesine konizasyon işlemi uyguland. Konizasyon işlemini kabul eden hastaların patolojileri: 7 hasta HSIL ve 1 hasta LSIL olarak bildirildi. Bir hastada cerrahi sinırlar pozitif olarak saptand. $\mathrm{Bu}$ hastaya rekonizasyon uyguland 1 ve HSIL rezidüel hastalık olarak saptandı.

Servikal biyopsi sonucu HSIL gelen 26 ASCUS sitolojisine sahip hastanın yirmi iki tanesine konizasyon işlemi uyguland. Konizasyon işlemini kabul eden hastaların patolojileri: 2 hasta servikal kanser, 17 hasta HSIL, 1 hasta LSIL, 2 hasta normal olarak bildirildi. Sekiz hastada cerrahi sınırlar pozitif olarak saptand1. Yedi hastaya rekonizasyon uyguland1, serviksi rekonizasyona uygun olmayan bir hastaya histerektomi uygulandi. İkinci operasyon sonrasi patoloji sonucunda altı hastada HSIL rezidüel hastalık olarak saptand1.

Tablo 1. Sitolojik grupların demografik ve patolojik olarak karşslaş̧ııılması

\begin{tabular}{|l|l|l|l|}
\hline & $\begin{array}{l}\text { ASCUS } \\
(111)\end{array}$ & LSIL (67) & $\mathrm{p}$ \\
\hline Yaş & $41(30-65)$ & $42(30-63)$ & 0,49 \\
\hline $\begin{array}{l}\text { HPV tipi } \\
\text { HPV 16- 18 } \\
\text { Diğer } \\
\text { yüksek } \\
\text { riskli HPV }\end{array}$ & $48(\% 43.2)$ & $21(\% 31.3)$ & 0.15 \\
\hline $\begin{array}{l}\text { Histopatoloji } \\
\geq \text { HSIL }\end{array}$ & $27(\% 24.3)$ & $11(\% 16,4)$ & 0.25 \\
\hline < HSIL & $84(\% 75.7)$ & $56(\% 83.6)$ & 0.17 \\
\hline $\begin{array}{l}\text { Konizasyon } \\
\text { sonrası } \\
\text { cerrahi sinır } \\
\text { pozitifliği }\end{array}$ & $8(\% 50)$ & $1(\% 14.3)$ & \\
\hline
\end{tabular}

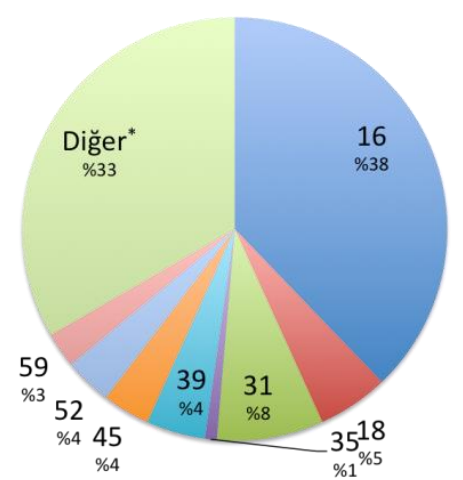

* KETEM tarafindan sadece diğer HPV pozitif olarak raporlanan olgular

Figür 1. ASCUS sitolojisi olan 111 olgudaki HPV tiplerinin dağılımı

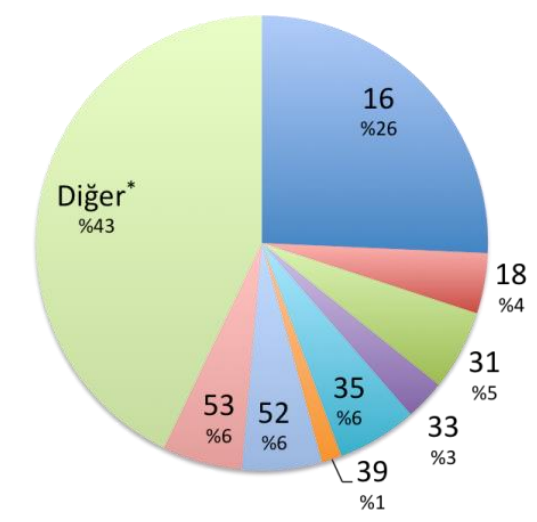

* KETEM tarafindan sadece diğer HPV pozitif olarak raporlanan olgular

Figür 2. LSIL sitolojisi olan 67 olgudaki HPV tiplerinin dağılımı

\section{Tartışma}

Çalışmamızın en önemli sonucu hem HSIL ve üzeri lezyonlarda hem de HPV 16 ve/ve ya 18 pozitif olgularda ASCUS ve LSIL grupları arasında istatistiksel anlamlı bir fark bulunmamasıdır. Ayrıca ikincil bir sonuç olarak ASCUS sitolojisine sahip olan olgularda HPV 16 ve/ veya HPV 18 pozitifliğinde diğer yüksek riskli HPV tiplerine göre HSIL ve üzeri lezyon bulunmas1 (sirasiyla \%41.7 ve\%11.1) daha yüksektir $(\mathrm{p}<0.001)$. Bilgimiz dahilinde bu çalışma ASCUS ve LSIL sitolojilerini HPV DNA sonuçları eşliğinde karşılaştıran ilk çalışmadır.

Uzun dönem prospektif çalışmalar HPV 16 pozitif bulunan kadınların diğer yüksek riskli HPV tipleri pozitif olan kadınlara göre CIN 3 ve kanser olma ihtimalinin daha yüksek olduğunu göstermiştir $(9,10)$. Stoler ver ark. 1578 ASCUS sitolojisine sahip kolposkopi 
uygulanan hastada HPV 16 pozitifliğinin diğer yüksek riskli HPV tiplerine oranla CIN3 ve üzeri lezyonları bulundurmasının rölatif riskini 4.5 (95\% CI, 2.5-8.2) olarak bulmuşlardır (11). Bizde bu çalışmaya benze şekilde çalışmamızda HPV 16 ve 18 grubunda diğer yüksek riskli HPV grubuna göre HSIL ve üzeri lezyonları daha yüksek oranda bulduk. Fakat güncel k1lavuzlar ASCUS yönetimini değiştirmeyeceği için bu olgulara HPV genotiplemesi önermemektedir (12).

Monsonego ve ark., ATHENA çalışmasındaki verileri inceledikleri çalışmalarında HPV alt tiplerine göre servikal biyopsi sonuçlarını detaylı olarak bildirmişlerdir (6). Bütün genotiplere bakıldığ 1 zaman anormal sitolojisi olan olgularda 92 hastada CIN3, 5 hastada servikal kanser saptamışlardır. Fakat anormal sitoloji sonuçlarını ayrıntılı olarak gruplandırmamışlardı. Katki ve arkadaşları 3064 yaş arası kadınlarda HPV pozitif olup ASCUS sitolojisine sahip olgularda LSIL sitolojisine sahip olgulara oranla CIN 3 riskinde minimal bir yükseklik saptamışlar (sirasiyla \%6.8 ve \%5.2), kanser riskinde de benzer şekilde minimal yükseklik bulmuşlardır (sirasiyla \%0.41 ve \%0.16) (4). Fakat maalesef LSIL olgularını HPV durumu hakkında değerlendirememişlerdir. Bizde çalışmamızda ASCUS ve LSIL grupları arasında Hem HSIL ve üzeri lezyonlar açısından anlamlı farklılık bulmamakla birlikte bütün olgularımız HPV DNA pozitifdi.

Güncel yayınlara bakıldığ zaman HPV 16 ve ya HPV 18 pozitif olan olgularda kanser oranının \%0.6 ila \%9.3 arasında değiștiği gözükmektedir $(6,13,14)$. Çalışmamızda sadece iki servikal kanser olgusuna rastlanırken bu olgular ASCUS sitolojisine sahipti ve birinde HPV 16 diğerinde HPV 39 pozitifliği mevcuttu.

Çalışmamızın kuvvetli yönü ASCUS ve LSIL sitolojisine sahip olguların HPV DNA tipleri ışı̆̆ında ilk kez incelenmiş olmasıdır. Her HPV tipi ayrı bir genetik tür olmasına rağmen baskın HPV tipleri birbirlerini etkileyebilir (15). Bu doğrultuda hem HPV 16 hem de HPV 18 pozitif olan olguları incelemek önem kazanmaktadır. Çalışmamızın diğer bir kuvvetli yönü ise sitolojisi normal olan olguların incelenmiş olmasıdır.

Çalışmamızın temel kısıtlaması tek merkezli bir çalışma olması ve geniş hasta sayısı içermemesidir. Ayrıca bazı HPV 16 ve HPV 18 pozitif olan olgulara diğer HPV tiplerinin pozitifliği de eşlik etmektedir. $\mathrm{Bu}$ birden fazla HPV pozitifliği bulunan olgular birbirlerini etkileyebilir. Bütün bu kısıtlamalara rağmen çalışmamızın bu konuyla ilgili olan sinırlı literatür bilgisine katkısı olacağına inanıyoruz.

Sonuç olarak hem HSIL ve üzeri lezyonlarda hem de HPV 16 ve/ve ya 18 pozitif olgularda ASCUS ve LSIL grupları arasinda istatistiksel anlaml bir fark bulunmamaktadır. Daha geniş hasta serilerini kapsayan çalışmalarla hem sonuçlar doğrulanmalı hem de bu olgulara eşlik eden invaziv servikal kanserler hakkında fikir sahibi olunabilir.

Conflict of interest: The authors declare that they have no conflict of interest

\section{REFERENCES}

1. Wright TC, Jr., Stoler MH, Behrens CM, Apple R, Derion T, Wright TL. The ATHENA human papillomavirus study: design, methods, and baseline results. Am J Obstet Gynecol 2012;206:46 e1- e11.

2. Massad LS, Einstein MH, Huh WK, et al. 2012 updated consensus guidelines for the management of abnormal cervical cancer screening tests and cancer precursors. Obstet Gynecol 2013;121:82946.

3. Katki HA, Schiffman M, Castle PE, et al. Benchmarking CIN 3+ risk as the basis for incorporating HPV and Pap cotesting into cervical screening and management guidelines. J Low Genit Tract Dis 2013;17:S28-35.

4. Katki HA, Schiffman M, Castle PE, et al. Five-year risks of CIN 3+ and cervical cancer among women with HPV testing of ASC-US Pap results. J Low Genit Tract Dis 2013;17:S36-42.

5. Katki HA, Schiffman M, Castle PE, et al. Five-year risks of CIN 2+ and CIN 3+ among women with HPV-positive and HPV-negative LSIL Pap results. J Low Genit Tract Dis 2013;17:S43-9.

6. Monsonego J, Cox JT, Behrens C, et al. Prevalence of high-risk human papilloma virus genotypes and associated risk of cervical precancerous lesions in a large U.S. screening population: data from the ATHENA trial. Gynecol Oncol 2015;137:47-54.

7. Bornstein J, Bentley J, Bosze P, Girardi F, Haefner H, Menton M, et al. 2011 colposcopic terminology of the International Federation for Cervical Pathology and Colposcopy. Obstet Gynecol 2012;120:166-72.

8. Darragh TM, Colgan TJ, Thomas Cox J, et al. The Lower Anogenital Squamous Terminology Standardization project for HPV-associated lesions: background and consensus recommendations from the College of American Pathologists and the

Adress for correspondence: Uzm. Dr. Ibrahim Yalcin Hacettepe Mh, Talatpaşa Blv, 06230 Samanpazarı/altındağ Ankara, Türkiye 
American Society for Colposcopy and Cervical Pathology. Int J Gynecol Pathol 2013;32:76-115.

9. Khan MJ, Castle PE, Lorincz AT, et al. The elevated 10-year risk of cervical precancer and cancer in women with human papillomavirus (HPV) type 16 or 18 and the possible utility of type-specific HPV testing in clinical practice. J Natl Cancer Inst 2005;97:1072-9.

10. Kjaer SK, Frederiksen K, Munk C, Iftner T. Longterm absolute risk of cervical intraepithelial neoplasia grade 3 or worse following human papillomavirus infection: role of persistence. J Natl Cancer Inst 2010;102:1478-88.

11. Stoler MH, Wright TC, Jr., Sharma A, et al. Highrisk human papillomavirus testing in women with ASC-US cytology: results from the ATHENA HPV study. Am J Clin Pathol 2011;135:468-75.

12. Massad LS, Einstein MH, Huh WK, et al. 2012 updated consensus guidelines for the management of abnormal cervical cancer screening tests and cancer precursors. J Low Genit Tract Dis 2013;17:S1-S27.
13. Lagos M, Van De Wyngard V, Poggi H, et al. HPV16/18 genotyping for the triage of HPV positive women in primary cervical cancer screening in Chile. Infect Agent Cancer 2015;10:43.

14. Zhang Q, Zhao M, Cao D, et al. Assessment of the effectiveness of HPV16/18 infection referred for colposcopy in cervical cancer screening in Northwest of China. J Med Virol 2017.

15. Plummer M, Schiffman M, Castle PE, MaucortBoulch D, Wheeler CM, Group A. A 2-year prospective study of human papillomavirus persistence among women with a cytological diagnosis of atypical squamous cells of undetermined significance or low-grade squamous intraepithelial lesion. J Infect Dis 2007;195:1582-9. 